\title{
THE ROLE OF SEMANTICS IN LINGUISTIC COMPETENCE
}

\author{
Muslima Karimova \\ Graduate Of Fergana State University, Uzbekistan
}

\section{ABSTRACT}

In second language acquisition, semantics assumes a heightened position of importance in regards to achieving target levels of competence. Assuming that the target competence is equal to a native-speaker's, a non-native speaker will never fully reach a native level of semantic competence. The ways that L1 semantics can affect L2 semantics is an area of interest in both cognitive and generative linguistics. Research from both perspectives is valuable to evaluate semantics at the lexical and syntactic level.

KEYWORDS: - Cognitive linguistics, second language, syntactic level, bilingual status, cognitive semantics, syntactic structures, components of a language, generative grammar, semantic interpretations, morphological component.

\section{INTRODUCTION}

The primary purpose of human language is to allow people to communicate about their experiences in the actual world. Language is the means via which all of these behaviors are carried out, whether it is spreading gossip, marking the location of a food source, admonishing youngsters, or disputing who purchased the last round. Language and the rest of the human experience are far too intertwined to be separated. Thoughts are communicated through language, but language may also influence how people think.

Semantic research is concerned with how the meanings of words, phrases, and grammatical structures are encoded in language. There are no precisely equivalent methods for perceiving the actual world through language in any languages. The relationship between a native language and the speakers' thinking can never be entirely understood. The semantics of the first language (L1) will influence the process of learning a second language (L2). A non-native speaker will fall short of a native goal level of semantic understanding if the L1 semantics have an influence on the L2 semantics.

Because some linguists have a propensity of adopting their own meanings of words, the definitions I'm employing for these terms are as follows. The first is native speaker; for the purposes of this study, a native speaker is defined as someone who learned a language before the age of eight and utilizes it as their primary means of communication, including bilinguals. It's also crucial to define L1 and L2. I refer to the learner's native language as L1; bilinguals will have their bilingual status 
CURRENT RESEARCH JOURNAL OF PHILOLOGICAL SCIENCES 2(11):

128-134, November 2021

DOI: https://doi.org/10.37547/philological-crjps-02-11-28

ISSN 2767-3758

(C)2021 Master Journals

Crossref do

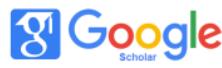

Accepted $25^{\text {th }}$ November, 2021 \& Published $30^{\text {th }}$ November, 2021

specified. I will not use L3, L4, etc. without specifically noting whether a language is a learner's L3. I will use L2 to mean any language learned after the native language(s); I will not use L3, L4, etc. without expressly indicating if a language is a learner's L3. Linguists have debated at length over the innateness of human language. Generative linguistics takes a minimalist position on the role of semantics in language. Cognitive linguistics does not attempt to separate linguistic and real world knowledge. The way in which language is used to covey the real world affects how speakers conceive the world around them. Cognitive linguistics assumes a maximized role of semantics in language. It allows for the study of meaning at not only the lexical level, but also the syntactic level. When acquiring a second language, the system of the L1 semantic conceptualization will affect the $\mathrm{L} 2$ in a way that will not allow for a native level of semantic comprehension to be acquired.

Cognitive and Generative Linguistics and Semantics The way semantics works within a specific language framework directly relates to how the framework treats language as a whole. Generative linguistics assumes a minimal role of semantics, which relates to the minimalist tendencies of generative grammar. Cognitive linguistics assigns a maximized role for semantics that mirrors the role given to language in the cognitive experience. Understanding the way semantics relates to generative and cognitive linguistics respectively facilitates an analyses of SLA research done from both perspectives.

\section{Generative Linguistics}

Generative linguistics began as a short book written by Noam Chomsky and has become the inescapable standard of linguistic study. Chomsky's theories rely on an assumed finite and universal genetic linguistic capacity in all normal human brains. Although revolutionary in its original place and time, the concepts of a generative grammar are being challenged with great frequency by linguists who acknowledge the difficulty in separating language from other cognitive processes. Because word meaning is the least universal aspect of a given language, bridging the gap between linguistic and real-world information can be difficult for generative grammar. Many external variables impact word meanings, and language is frequently flexible and never fully established. The emergence of the term tweet is a recent example of language flexibility. Tweet was once thought to be a bird's call. With the rise of Twitter, the noun tweet can now refer to a microblog entry of 140 characters or fewer; the verbal form, to tweet, refers to the production of the aforementioned microblog item rather than sound. Because it's so difficult to pin down word meanings in a particular language, generative grammar theorists have given semantics a limited role. "The essential structure of a phrase is a syntactic one, and semantics only comes in as an interpretation of those syntactic components," according to Interpretative Semantics (Geeraerts, 2010 , p. 109). This is in contrast to the original idea of Generative Semantics, which claimed that the underlying sentence structure was a merger of semantics and syntax. Accepting Interpretative Semantics instead of Generative Semantics in generative grammar represents a significant break that eventually leads to cognitive semantics. Interpretative Semantics is more restricted than Generative Semantics. It conforms to typical UG theories by limiting semantics to the interpretation of underlying syntactic structures. On the other side, Generative Semantics is less restrictive and permits the function of semantics to pervade the grammar. Some proponents of Generative Semantics say that a sentence's fundamental structure is semantic, while others argue that it is a semantics/syntax mix. Clearly, the syntax-first character of generative grammar theory corresponds to the minimalistic role assigned to semantics; yet, this devaluation of semantics 
CURRENT RESEARCH JOURNAL OF PHILOLOGICAL SCIENCES 2(11):

128-134, November 2021

DOI: https://doi.org/10.37547/philological-crjps-02-11-28

ISSN 2767-3758

(C)2021 Master Journals

Crossref do

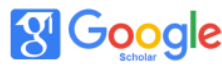

Accepted $25^{\text {th }}$ November, 2021 \& Published $30^{\text {th }}$ November, 2021

restricts the interaction between language and the actual world. As a result, Generative Semantics strives to maximize semantics' relevance in linguistic theory.

Chomsky's acceptance of the limited Interpretative Semantic framework into generative grammar represents a watershed moment in cognitive linguistics and cognitive semantics. In response to Interpretive Semantics in generative theory, a language model was developed that prioritized semantics and the actual world, continuing the tradition begun by Generative Semantics. The maximization of semantics in language was accepted by cognitive linguistics. Every facet of language will be given significance since it is a part of the total human cognitive experience.

\section{Cognitive Linguistics}

Cognitive linguistics is the alternative to theories centered on around a generative grammar. Developing along side with cognitive psychology, sociology, anthropology, and other social sciences, it often draws on theories from these fields and applies them to language. In regards to my argument, cognitive linguistics provides the most clear cut hypotheses that can explain the difficulty a non-native speaker faces when acquiring an L2.

The context in which a language is spoken has a significant impact on the meaning of its signals. A linguistic environment devoid of vehicles but abundant in reindeer would not need to categorically distinguish between a truck, car, van, sedan, or other vehicle, but would do so strongly between reindeer species. Applying this to the field of SLA, it's clear that a learner with a poor L1 in a category with a high L2 will struggle to understand the intricacies of the linguistic indicators in the category.

Individual lexical elements and complete syntactic structures are given semantic significance by applying semantics to all components of a language. Every component of language is a sign of something if language is a communication system of abstracted symbols used to express real-world notions. As a result, a grammatical statement like Jason hit Tommy contains more than just syntax; it also has conceptual and semantic meaning as the prototype for a basic transitive sentence: Agent-Verb-Patient. Prototypes and prototype theory are important parts of cognitive semantics that will be covered in detail later. Because of its critical position in cognitive linguistic theory, semantics is tremendously essential.

In the field of SLA, semantics plays a role in both the generative and cognitive traditions. SLA is studied holistically by cognitive linguists, who emphasize the context, usage, and interaction between language, mind, and development. These goals, together with the increased importance of semantics, demonstrate that the cognitive tradition does not strive to separate language and real-world information, as generative grammar does, but rather welcomes their interdependence.

SLA is a process of remapping semantic features on to new forms and resetting parameters from the L1 to those appropriate for the L2. Generative SLA theories rely on the assumed universality of language, arguing that SLA is a process of remapping semantic features on to new forms and resetting parameters from the L1 to those appropriate for the L2. In the sense that semantics solely influences the interpretation of syntactic structure, the minimum function of semantics is preserved. The following study will demonstrate that semantics is critical to the SLA process and can lead learners to fall short of the native-like target level of learning.

Research and Theories on Semantics in Second Language Acquisition

Generative SLA Research and Theories

SLA researchers maintain the minimalist role of 
CURRENT RESEARCH JOURNAL OF PHILOLOGICAL SCIENCES 2(11):

128-134, November 2021

DOI: https://doi.org/10.37547/philological-crjps-02-11-28

ISSN 2767-3758

(C)2021 Master Journals

\section{sones}

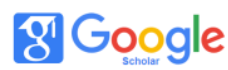

Accepted25 $5^{\text {th }}$ November, 2021 \& Published 30th November, 2021

Interpretative Semantics. Cognitivists accept a larger role of semantics in their research. Donna Lardiere examines the role of semantic features in an L2 and how it relates to the learner's L1 semantic features. She studies how a learner with a universal set of available features maps the L2 features on to L2 forms. The Natural Semantic Metalanguage assumes that all languages have a lexical or morphological component that situates an action as occurring before or after another action. Geeraerts, 2010, argues that languages like Yukatek Maya do not have any lexicalized representation of these primitive features. Lardiere (2009) discusses English, Korean, and Mandarin Chinese speakers' usage of accurately assembled L2 lexical items as an example of feature assembly.

The similarity of an L2 feature to an L1 is a major factor in the ability of a learner to fully map that feature. For example, a specific native Korean structure that indicates the use of -tul that has no similar structure or conceptualization in English would cause errors in acquisition. In the minimalist view, the semantic interpretations of a syntactic construction rely on the features of each lexical item's functional category. Extending this to Lardiere's observation, if a L2 functional category contains features that comprise a different functional category in the L1, the learner will be hindered in remapping these different features. Slabakova and Montrul found that even the highest level of L2 learners were unable to reach nearnative levels of comprehension or acceptance of aspectual shifts caused by coercive phrases.

Perez-Leroux, et al. found that the non-natives were significantly lower in ability than native speakers and exhibited an inability to accept a specific tense in coerced contexts where native speakers did. This shows that the semantic effects of coercive phrases were not being comprehended by these non-native speakers. The data here shows a lack of native- like semantic comprehension, which suggests some issues in acquisition. The various ways that languages raise verbs syntactically are not crosslinguistically universal. When a learner's L1 diverges from an L2 in verb raising strategies, a conflict occurs in acquiring the L2 semantic effects. L2 speakers of languages with the greatest difference in verb-phrase strategies from their L1 had the most difficulty. This study shows that a native-like level of comprehension does not mean a total lack of comprehension. The more similar a L1 is to the L2, the more likely the learner is to have a higher level of comprehension and accuracy in production.

Diaz, et al. (2008) implies that an inability to accept native constructions can suggest an incompatible semantic-concept relation in theL 2 because of the L1. Lardiere (2009) investigated the acquisition of a morphosyntactic feature in Korean. Rather than assuming that the participants tested failed to match native levels of comprehension due to the Korean feature being unselected in the 11 , a maximized role of semantics would suggest that the issues arise from conceptual differences between the two.

\section{Cognitive SLA Research}

The cognitive tradition maximizes the role of semantics, extending it to syntactic structures along with lexical entries. By doing this, cognitivists accept that a given syntactic structure has semantic meaning as do the individual lexical items. A passive sentence like Tommy was hit by Jason indicates that the speaker emphasizes the recipient of the action and removes the impact of the agent, Jason. In Dutch, both between and among are realized by the single preposition tussen. While English explicitly delineates when $\mathrm{Y}$ is between $\mathrm{X}$ and $\mathrm{Z}$ from when it is among them, Dutch treats both concepts as equivalent.

This is also true of English over/above and from/of 
CURRENT RESEARCH JOURNAL OF PHILOLOGICAL SCIENCES 2(11):

128-134, November 2021

DOI: https://doi.org/10.37547/philological-crjps-02-11-28

ISSN 2767-3758

(C)2021 Master Journals

Crossref do

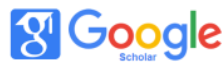

Accepted $25^{\text {th }}$ November, 2021 \& Published $30^{\text {th }}$ November, 2021

in relation to Dutch boven and ven, respectively. These terms presented the greatest challenge for the participants studied to accept and produce accurately and in native contexts. Lowie and Verspoor (2004) found that when a L2 lexical item is similar to an L1 it is easier to acquire. This is especially true for phonologically similar terms like Dutch aan and English on which are cognates. For example, in Spanish, to attend is asistir and to assist is atender (unless they are transitive verbs, in which case the meanings switch to being similar to English).

These "false- cognates" are tricky to acquire accurately. As for frequency, English prepositions that are not frequent caused the Dutch speakers to revert to L1 knowledge to attempt to comprehend the utterance. This study shows the multitude of factors that influence acquisition.

Cognitive semantics examines two main components: the lexeme and the lemma. Lemmas are abstractions of the semantic and syntactic information while lexemes are orthographic/phonological symbols. Lemma is not a language specific entity of semantic knowledge; but rather, is a mental category of knowledge that is accessed by both the L1 and L2 lexeme to which it correlates. A L1 that does not make conceptual distinction between concepts that are distinct in a L2 will cause a learner to have issues acquiring, using, and comprehending the distinction. The essence of the lexeme/lemma distinction can be applied to phrasal semantics similarly as it is in lexical semantics.

At the verbal phrase level, the tense, aspect, and transitivity of the verb may indicate certain semantic information in the L1 that is not present in theL2. Take for example the difference between Amanda hates Hillary and Hillary is hated by Amanda. The first construction assigns agency of the hatred to Amanda and indicates that Hillary is the recipient of hate. The second construction degrades the agency of Amanda and increases the role of Hillary in the action of being hated. The importance of the lemma in a cognitive view of language is that it contains specified and unspecified semantic information.

If an L1 does not delineate an active/passive construction or if it assigns a more dramatic degradation of agency in the passive, there will be an issue in comprehending the subtly of the two constructions. Conceptual relations and metaphoric extensions mark another area where a non-native speaker may fall short of a native target level.

The semantics of a language are crucial to the ability to accurately use and comprehend the language. Lagrou, et al. (2012) researched the effects of L1 phonology and phonotactics on accessibility of the L2 lexicon. They found that similarities between L1 and L2 Lexemes cause the learner to fall short of the target level of semantic comprehension. Acquiring a native-like level of semantic comprehension means that the acquirer must be able to accurately use and comprehend semantic nuances in L2 contexts. Slabakova and Montrul (2008) show that the verbal system of the L1 affects L2 learners' ability to accept syntactic constructions that native speakers accept.

The relationship between L1 and L2 semantics permeates all levels of linguistic study and causes non-native speakers to fall short of a native level of comprehension. Examining the lexeme/lemma relationship in regards to SLA, Lowie and Verspoor (2004) and Largou et al. (2012) highlight the effects on both the Lexeme and lemma levels.

\section{The Relationship Between Semantics and Thought}

Language and thought have always had strong ties in theoretical terms. If language is a medium through which humans covey their thoughts, ideas, 
CURRENT RESEARCH JOURNAL OF PHILOLOGICAL SCIENCES 2(11):

128-134, November 2021

DOI: https://doi.org/10.37547/philological-crjps-02-11-28

ISSN 2767-3758

(C)2021 Master Journals

Crossref do

gil Google

Accepted $25^{\text {th }}$ November, 2021 \& Published $30^{\text {th }}$ November, 2021

and comments about their reality, then what effects does that reality and now it is thought about have on the language? It is certainly not the case that language precedes thought; however, there is an important relationship between language and thought. The Sapir-Whorf hypothesis posited that the way a speaker categorizes objects in the real world relates to the conceptual categories of their native language. Weak applications of linguistic relativity have shown that there is a relationship between real world conceptualization and linguistic conceptualization. This can cause issues in the acquisition of a second language because of the vast differences possible between the way that the L1 and L2 conceptualize and code real world information linguistically.

The L1 and L2 conceptualizations of conceptual categories will influence the acquisition of the L2's conceptualization system. Each member of a category bears some resemblance to some of the others, but not necessarily equal resemblance to all. Common features of all members of a conceptual category are not enough to delineate what the category is. All of these concepts are specific to each language and to the conceptual categories already present within that language. The development of cognitive functions coincide with linguistic development highlights the link between language and thought.

Gopnik (2001) presents data from a study of Korean, and English speaking toddlers' categorization of blocks of various shapes and colors and verbal reasoning strategies. When the toddlers were talking about the task, the Korean toddlers used more complex verbal forms than the English toddlers. All of this information taken together indicates a direct link between the development and usage of thought and the development of cognition.

The issue of saliency and prototypicallity is extremely important to analyzing the role of semantics in SLA. All lexical entries and syntactic constructions exist on a continuum based on their salient features and relation to the prototype of the given category. If transitive verbs like hit are the prototype, verbs that require three participants, like send, or do not clearly indicate the patient's change of state, like love, would be less prototypically transitive. Learners may make overgeneralizations of central concepts if the prototypical English determiner is the, it may be used in contexts where it is not the appropriate determiner. The process of acquiring an L2 requires learners to conceptualize the world in the terms of the L2. This is not to say that the learner must think exactly like a native speaker; however, a similar system of conceptual categorization must develop.

Jarvis and Pavlenko (2008) examine the impact of L1 semantics on the L2 especially in regards to lexicosemantic transfer. They argue that during earlier stages of acquisition, learners may use an authentic L2 word in a way that appropriates its meaning based on L2 and L1 semantic information. Divergence or negative convergence-like falsecognates or conceptual delineations - in any area of the L1 and L2 can cause the learner to fail to acquire a native-like semantic comprehension.

\section{Conclusion}

Semantics simply is the relationship between meaning and form. In cognitive linguistics, the role of semantics is maximized to the point where all areas of inquiry are affected by it. The role semantics plays in a given linguistic tradition is extended to its role in SLA. When acquiring an L1, a learner is entering into a language with its own specific categorizations and conceptualizations about the world. Differences between the L1 and L2 can cause learners to fall short of acquiring a nativelike target level of acquisition.

A non-native speaker has two distinct 
CURRENT RESEARCH JOURNAL OF PHILOLOGICAL SCIENCES 2(11):

128-134, November 2021

DOI: https://doi.org/10.37547/philological-crjps-02-11-28

ISSN 2767-3758

(C2021 Master Journals

crossref do) 8: Google

Accepted $25^{\text {th }}$ November, 2021 \& Published $30^{\text {th }}$ November, 2021

conceptualizations of the world through which they can communicate. The L1 can facilitate acquisition in areas of similarity, whether actual or perceived, and can hamper acquisition in areas of dissimilarity.

\section{REFERENCES}

1. Archard, M. \& Niemeier, S. (Eds.). (2004). Cognitive linguistics, second language acquisition, and foreign language teaching. Berlin: Mouton de Gruyter.

2. Athanaiadou, A. (2004). Teaching temporal connectors and their prototypical nontemporal extensions. In M. Achard \& S. Niemeier (Eds.)., Cognitive linguistics, second language acquisition, and foreign language teaching. (p. 195-210).

3. Berlin: Mouton de Gruyter.

4. Denham, K., \& Lobeck, A. (2010). Linguistics for everyone: An introduction. Boston, MA: Wadsworth/Cengage Learning.

5. Diaz, L., Bel, A., \& Bekiou, K. (2008). Interpretable and uninterpretable features in the acquisition of Spanish past tenses. In J.M. Liceras, H. Zobl, \& H. Goodluck (Eds.), The role of formal features in second language acquisition. (p. 484-512). New York, NY: Lawrence Erlbaum Associates.

6. Dirven, R. \& Verspoor, M. (1998). Cognitive Exploration of Language and Linguistics.

7. Amsterdam: The Netherlands: John Benjamins Publishing Co.

8. Geeraerts, D. (2010). Theories of lexical semantics. New York, NY: Oxford University Press Inc.

9. Gopnik, A. (2001). Theories, language, and culture: Whorf without wincing. In $\mathrm{M}$. Bowerman \& S. Levinson (Eds.), Language acquisition and conceptual development. (p. 45-69). New York, NY: Cambridge University Press.

10. Hawkins, R., Casillas, G., Hattori, H., Hawthorne, J., Husted, R., Lozano, C., Okamoto, A., Thomas, E., \& Yamada, K. (2008). The semantic effects of verb raising and its consequences in second language acquisition. In J.M. Liceras, H. Zobl, \& $\mathrm{H}$.

11. Goodluck (Eds.), The role of formal features in second language acquisition. (p. 328-351). New York, NY: Lawrence Erlbaum Associates.

12. Koerner, E. F. K. (1973). Ferdinand de Saussure; origin and development of his linguistic thought in Western studies of language: A contribution to the history and theory of linguistics. Braunschweig: Vieweg. 